\title{
Factors Influencing Research Activity among Medical Students at University of Nairobi
}

Authors: Ogeng'o J.A., BSc, MBChB, PhD, Mwachaka P.M. BSc, Bundi P.K., BSc, Affiliation: Department of Human Anatomy, University of Nairobi, P.0. Box 00100 - 30197, Nairobi - Kenya, Corresponding author: Philip Maseghe Mwachaka, Email: pmaseghe@gmail.com, Tel: 0723353913

\author{
Abstract \\ Background \\ Undergraduate student research activity facilitates their independent \\ thinking, interest in evidence based practice and preparation for \\ graduate programmes. Reports from African Universities are, however, \\ scarce. This study aimed at describing the factors that influence \\ research among medical students in a Kenyan University. \\ Subjects and Methods \\ This descriptive cross sectional study involved medical students \\ at the School of Medicine, University of Nairobi. An open question- \\ naire regarding research activity was administered to 150 medical \\ students. Responses were analyzed for year of study, attitude, partici- \\ pation, stimulants, deterrents and publication output. \\ Results \\ One hundred and twenty two (81.3\%) responses were analyzed. Ma-
}

jority (50.8\%) were in fifth year. Of the respondents $81.6 \%$ expressed interest in participating in research, but only $38.4 \%$ of them had participated in research with $13.7 \%$ taking part in writing a research paper.

Stimulants included contribution to advancement of knowledge (54.1\%) and fulfillment of academic requirements (51.4\%). Major deterrents were lack of research mentors (51.9\%), knowledge of research methods (37.7\%) and funding (29.9\%). Of 41 published papers, $85.4 \%$ were co-authored with faculty.

Conclusion

Lack of mentors, training in research methodology and funding are main deterrents. Inclusion of research methodology in curricular, enhanced faculty involvement and budgetary support for research are recommended.

\section{Introduction}

Undergraduate student participation in research is important in motivating them to become independent thinkers, preparing them for graduate programmes and facilitating their interest in research based practice $(1,2)$. Further, it forms part of the continuum of learning process (3). In the United States, it has been advocated as an innovative strategy to improve higher education (4). In spite of these universal benefits, there is wide diversity in level of undergraduate student involvement in research. For example, while in the USA, frequency of student research experiences has increased, and in Germany medical students are among the authors in nearly 30\% of all indexed papers from medical school (5), in some Indian and Scandinavian universities, over $90 \%$ of the students have no research interest or experience $(6,7)$. Data on this subject are important in informing research and development programmes. Reports from Africa, are however, scarce. This study therefore investigated factors that influence research among undergraduate medical students in a Kenyan University.

\section{Subjects and Methods}

The study was conducted at the School of Medicine in the University of Nairobi. The school has a student population of 2000, distributed equally in 5 academic levels. In the Intercalated Bachelor of Science in Human Anatomy and Medical Physiology programmes offered by the school, students are required to conduct original research and submit a dissertation before award of degree. A random sample of 150 students from levels 2 to 5 were involved in the study. They were drawn from those who had attended a weekly clinical presentation. A questionnaire was administered to all those present at the meeting without prior knowledge of the investigation. The questionnaire collected level of study, whether or not one had participated in research, or in writing a research paper. Respondents were also required to voluntarily declare their attitude towards research and factors that influenced their participation. The data were coded and analyzed by statistical package for social scientists (SPSS) version 13.0 for windows. 


\section{Results}

\section{Demographics}

One hundred and twenty five out of $150(83.3 \%)$ students completed the questionnaire. Three students did not indicate their year of study and were therefore excluded. One hundred and twenty two were analyzed. Male to female ratio was $1.14: 1$. Response by year of study is summarized in Fig.1.

\section{Attitude towards Research}

Majority (81.6\%) of the students were excited about participating in research. One hundred and twenty one students (99.2\%) believed that research has a role in advancing medical knowledge. Of these $120(96.8 \%)$ were willing to take part in a scientific research workshop in order to gain knowledge on research methods. Seventy nine $(63.2 \%)$ read scientific or medical journals. The common journals read included: East African Medical Journal, Nairobi Journal of Medicine, New England Journal of Medicine, British Medical Journal, Science and Nature.

\section{Stimulants of participation in research}

Only $48(38.4 \%)$ students had previously participated in research projects. Of these, 25 (52.1\%) had undertaken the Intercalated Bachelor of Science Anatomy or Physiology course. The average number of research projects per student was $2.32 \pm 2.16$, with a minimum of one project and a maximum of ten projects. The main reasons for participating in research were to help contribute to knowledge (54.1\%) and to fulfill an academic requirement $(51.4 \%)$. Other reasons were to facilitate entry into post graduate programs and for financial gains (Fig.2).

\section{Deterrents to research}

For the 77(61.6\%) students who had never participated in research, major deterrents were lack of research mentors $(51.9 \%)$, knowledge of research methods $(37.7 \%)$ and funding (29.9\%). Some students believed that research was time consuming, challenging, and not interesting (Fig.3).

\section{Publication Output}

Seventeen $(13.7 \%)$ of the students surveyed had participated in writing a research paper. Fourteen of them

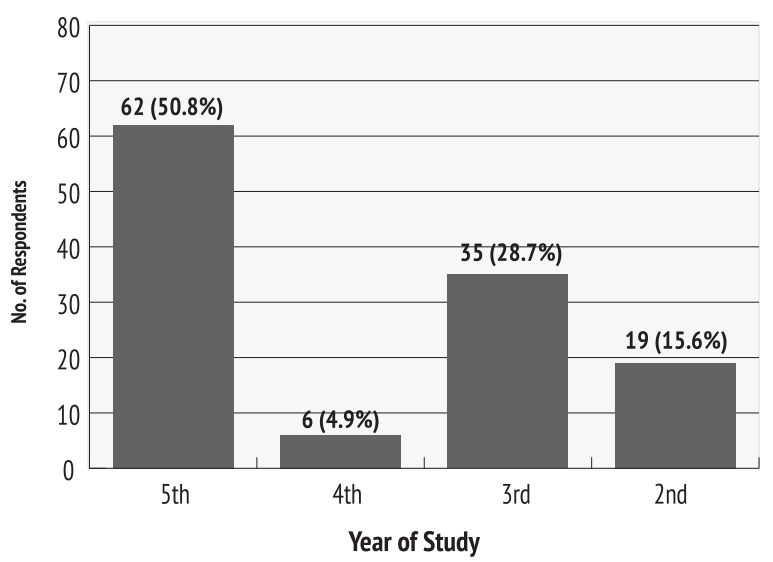

Figure 1: Response according to year of study

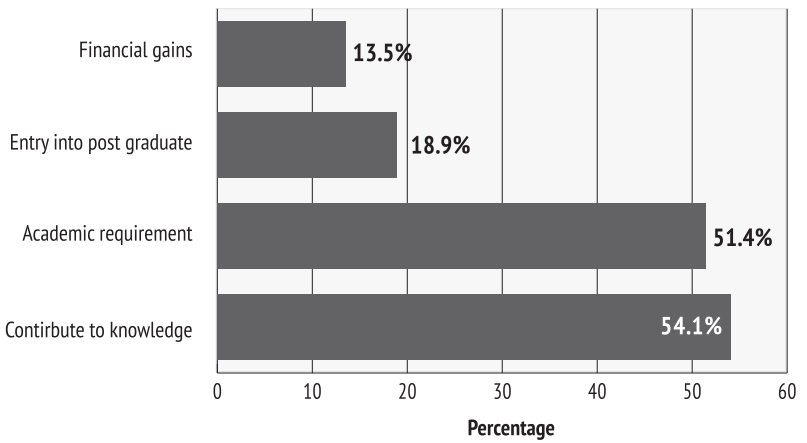

Figure 2: Reasons for participating in research

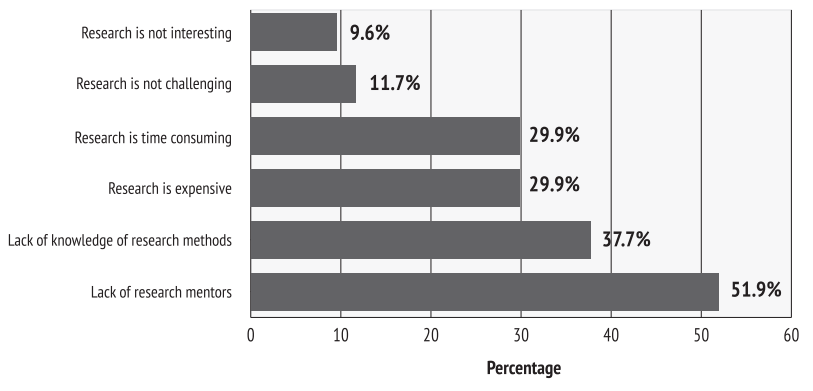

Figure 3: Reasons for not participating in research 
Factors Influencing Research Activity among Medical Students at University of Nairobi

Ogeng'o J.A., Mwachaka P.M., Bundi P.K.

$(82.4 \%)$ were from the Intercalated Bachelor of Science programmes. These groups had published a total of 41 papers (average of 2.41). The minimum number of publications per student was one while some students had a maximum of ten publications. Seven students published a total of 8 papers while in second year of medicine. Four students published 10 papers in their third year of study, nine published 18 papers while in fourth year, and three published a total of five papers while in fifth year. Most of these papers, $(85.4 \%)$, were co-authored by lecturers, while 6 papers involved only fellow students.

\section{Discussion}

Over $90 \%$ of the respondents believed research was important as it advanced medical knowledge. This is comparable to $92 \%$ in a study in South Africa (8). It is, however, at variance with reports from Scandinavian countries and India where students did not see reasons why they should be engaged in research as they did not perceive its relevance in their future careers $(6,7)$. These findings indicate that student interest in research varies from one country to another, probably depending on curriculum requirements and motivation from faculty and administration. Indeed, it has been shown that students who are under competent, motivating and supporting mentors undertake rigorous research projects (10). Secondly in universities where research is a curriculum requirement, undergraduate participation is high $(5,11)$.

Nearly $40 \%$ of respondents had previously participated in research to help contribute to knowledge, fulfill an academic requirement or facilitate entry to graduate programme. These figures and reasons are comparable to those given by students at University of Helsinki (12) and in South Africa (8). This suggests that there is great potential for increasing research output considering that $81.6 \%$ are excited about participating in research and $96.8 \%$ are willing to take part in a workshop to gain knowledge on research methods. Research in African universities is often hampered by financial constraints (13). Accordingly, investment by developing countries in undergraduate student research may constitute a viable way of improving the contribution of African Universities to National Research effort towards technological innovations to enhance quality of life of their people. Observations of the current study reveal, similar to literature reports from other universities $(6,11)$ that lack of mentorship, ignorance of research methodology, financial and time constraints are the major deterrents to undergraduate research. This suggests that provision of early mentorship, financial resources and entrenching it in the curriculum constitute viable measures of enhancing undergraduate research. Indeed, changes in curricular and grading systems, increased funding, mentorship, awarding credit to research, early exposure to research methodology; giving emphasis to research during postgraduate selection and promotion of inter-institutional collaborative research have been proposed (14). A pertinent observation of the current study is that most of the research projects were by students undertaking intercalated Bachelor of Science courses, in which time was protected, research methods taught, mentorship guaranteed and funding provided.

In recent years, there has been growing interest among students in the laboratory and clinical disciplines to participate in scientific research and many of them are publishing in high quality journals $(5,12)$. Consistent with this is the finding that in the current study nearly $14 \%$ of the students published 41 papers in peer reviewed journals. This constituted $13.6 \%$ of the total school output in the period concerned. This is lower than $28 \%$ in a German study (5) but is nonetheless a significant contribution to research output of the school. This is concordant with literature reports that student research activity can significantly influence publication output of a medical school $(5,15)$, and is at variance with some reports that few teams submit papers to refereed journals (10). This comparatively lower output may be due to financial constraints, lack of mentorship and fora at which to present student research work. Most (85.4\%) of the papers were co-authored by lecturers, who had supervised the intercalated BSc projects. This supports the suggestion that publishing research with students as co-authors constitutes an important component of educating future scientists (16). Indeed, there is a positive correlation between undergraduate and postgraduate research $(17,18)$. Accordingly research based undergraduate programmes where close supervision is provided should be encouraged.

\section{Conclusion}

Most medical students are enthusiastic about research, but less than $40 \%$ of them actually participate mainly 
to advance knowledge or fulfill academic requirements. Lack of mentors, training in research methodology and funding are main deterrents. Inclusion of research methodology in curricular, enhanced faculty involvement and budgetary supported for research are recommended.

\section{Acknowledgements}

We would like to thank the medical students for voluntary participation in the study, and Catherine Chinga for typing the manuscript.

\section{References}

1. Merkel C. Undergraduate research at Research University. New Directions for teaching and learning 2003; 93: 39 53.

2. Schwartz A, Hupert J. Medical students application of published evidence: Randomized trial. BMJ 2003; 326 : 536 - 538.

3. Gonzalez C. Undergraduate research, graduate mentoring, and the University's mission. Science 2001; 293 $1624-1626$.

4. Hu S, Kuh GD, Gayles JG. Engaging undergraduate students in research activities: Are research universities doing a better job? Innovative Higher Education 2007; 32 : $167-177$.

5. Cursiefen C, Altunbas A. Contribution of medical student research to the medline-indexed publications of a German medical faculty. Med educ 1998; 32: 439 - 440.

6. Aslam F, Shakir M, Qayyum MA. Why medical students are crucial to the future of research in South Asia Plos Med 2005; 2: e322.

7. Murtonen M. University students research orientations: do negative attitudes exist toward quantitative methods.
Scand J of educ research 2005; 49: 263 - 280.

8. Grossman ES, Naidoo S, Final year South African dental student attitudes toward a research component in the curriculum J Dent educ 2009; 73: 1306 - 1312.

9. Zier K, Alex S-G. A multifaceted programme to encourage medical students research. Acad Med 2001; 76: 743 - 747.

10. Tan EB. Research experiences of undergraduate students at a comprehensive university. Int J Teach Learn High Edu 2007; 19: 205 - 215.

11. Rosenblatt RA, Desnick L, Corrigan C, et al. The evolution of a required research program for medical students at the University of Washington School of Medicine. Acad Med 2006; 81: $877-81$.

12. Remes V, Helenius I, Sinisaari I. Research and medical teacher 2000; 22: $164-167$.

13. Benneh G. Research management in Africa. Higher education policy 2002; 15: 249 - 262.

14. Dangayach NS, Kulkarni VP, Panchabhai TS, Mentoring medial student research through studentships and fellowships: Reflections from India. J of postgrad. Med. 2009; 55: $152-153$.

15. Celec P, Hodosy J. Student scientific activity at the Bratislava medical faculty 2000 - 2004. A sciento metric study. Centr Eur J Med 2006; 1: 172 - 178.

16. Tobochnick J. The importance of undergraduate research. Am J Phy 69:1.

17. Segal S, Lloyd T, Houts PS, et al. The association between students' research involvement in medical school and their postgraduate medical activities. Acad Med 1990; 65: $530-533$.

18. Reinders JJ, Kropmans TJ, Cohen-Schotanis J. Extracurricular research experience of medical students and their scientific output after graduation. Med educ 2005: 39: 237. 